\title{
A proposed empirical corrosion model for reinforced concrete
}

\author{
M. B. Roberts, C. Atkins, V. Hogg and C. Middleton
}

\section{Slager and B. N. Sharp, Halcrow Group Limited}

The paper is important and timely. The practical application of analytical methods for durability design and the agreement of models that can be built into codes of practice are urgently required for important infrastructure. A key point made in the latest BRE Durability by Intent Workshop Report ${ }^{16}$ is that prescriptive approaches to durability design may be adequate for the generality of structures, but that long service life structures in aggressive conditions need a more sophisticated approach. BRE noted that such approaches may involve modelling of deterioration mechanisms, a conscious approach to service life design and a probabilistic approach to the likelihood of deterioration in a given time. They also noted that even in the current latest round of European Standards (i.e. including the recent EN $206{ }^{17}$ ) the approach to durability design is essentially prescriptive. Nevertheless, the framework for environmental classification and consideration of separate durability mechanisms in EN 206 and the forthcoming Complementary British Standard BS $8500{ }^{18}$ assist the process of developing analytical methods, as was explained in Concrete Society Report 109. ${ }^{19}$

The background to EN 206 and to the Complementary British Standard BS 8500 is given in a series of articles in Concrete June 2000, ${ }^{20-25}$ together with an article on the latest revision of BS 6349 Part 1 for maritime structures. ${ }^{26,27}$ The latter is significant in that it is the first design code that opens the door to analytical and probabilistic methods of durability design.

We have been interested in the corrosion model for reinforced concrete in a marine environment for almost 20 years in an attempt to improve on the relatively poor durability obtained from applying the prescriptive methods recommended by earlier codes and standards. Between us we have also been involved with the drafting of the latest BS 6349 and on the chloride sub-committee to the forthcoming Complementary British Standard to EN 206, so we can comment with some insight into their development. There are a number of points that arise from the paper which, with further explanation, may provide further insight to assist the development of a much needed consensus on general corrosion models for reinforced concrete in chloride environments.

The authors note that the actual chloride diffusion coefficients found from an extensive literature review differ by orders of magnitude from the 'observed, actual values' (presumably obtained by best-fit analysis of the chloride profiles found in the Midlands Links bridge structures) listed in Table 1. We suggest that there may be two reasons for this.

First, the values obtained from a literature review will likely cover a range of concrete qualities and cement types, whereas the structures of the Midlands Links are likely to have a more consistent and relatively uniform quality. Our recent investigations of chloride profiles in a number of bridge foundations on the M5 motorway have shown the concrete from a variety of exposure conditions with a range of different chloride profiles that were built around the same time, probably to similar specifications, have very similar apparent chloride diffusion coefficients. We note that the apparent diffusion coefficient of $220 \mathrm{~mm}^{2} /$ year (or $7 \times 10^{-12} \mathrm{~m}^{2} / \mathrm{s}$ ), obtained from the chloride profile data from two cross-beams and used in the Midlands Links model, would appear to be typical for a Portland cement concrete which had a water/ cement ratio of approximately 0.55 from comparison with values in the literature. ${ }^{28}$ It is not clear from the paper, however, how this value relates to the proposed effective parameter values set out in Table 1 and the cement type has not been stated. Further explanation would be useful.

Second, we note that the authors have assumed a steady increase in the effective surface chloride concentration to take account of annual de-icing salt applications. Effectively, this doubles the apparent diffusion coefficient compared with assuming a constant effective surface chloride coefficient equal to the final value over the period in question, as often assumed for maritime conditions because the level of surface chloride has been found to stabilise after only a few years. ${ }^{28}$ Do the authors have any data to show the rate of increase of effective surface chloride concentration with time? This may be a significant difference between bridge structures and maritime structures due to the different environmental conditions. It may also partly explain the difference between the theoretical and empirical corrosion models shown in Figs 12 and 13.

We assume that the surface chloride values given in Table 1 relate to the mass of sample, whereas the critical chloride concentrations relate to the mass of cement (notwithstanding 
the statement in paragraph 9 that all chloride values are given as a percentage with respect to the cement). On that basis, we note that the range of effective surface chloride concentrations observed in Midlands Links structures is similar to that found in Portland cement concretes exposed to maritime conditions (i.e. 3-5\% $\mathrm{Cl}$ by mass of cement). To allow more accurate comparison, can the authors advise on the cement content of the concrete?

We note that the authors have assumed that the initial chloride content of the concrete was zero. Acid-soluble chloride determinations for bridge structures from our investigations indicate background levels of approximately $0 \cdot 2 \% \mathrm{Cl}$ ion by mass of cement. In assuming $0 \%$ initial chloride, are the authors assuming negligible built-in chlorides or have only ingressing chlorides been considered in equation (3) for the initial and critical chloride concentrations?

A significant feature of the Midlands Links model described in the paper is that chloride-induced corrosion of the reinforcement has been assumed to be a two-stage process, with the corrosion rate assumed constant immediately after the chloride concentration at the reinforcement has reached a fixed critical level for all microenvironments around the structures. Many papers have been written which concentrate on the initiation phase and ignore what we believe is the much more important, and difficult, propagation phase. The authors have shown from their empirical model that the initiation phase can be relatively short, which is in agreement with our experience of maritime structures, assuming, as the authors of this paper, that the corrosion threshold level for steel in concrete is $0 \cdot 3 \% \mathrm{Cl}$ ion by mass of cement. All the effort, therefore, of many workers in this field has gone on modelling what we believe to be the least sensitive part of the deterioration process. By ignoring the propagation phase, the only way in which realistic results could be obtained for time to first cracking was by adopting much higher corrosion threshold values. Because such a range of assumptions has been adopted, code committees have looked askance at analytical models through lack of consensus on the modelling techniques and have kept to the prescriptive approach.

More recently, a three-stage approach has been put forward ${ }^{29}$ comprising corrosion initiation, propagation to first cracking, then propagation to a defined limit state of cracking, spalling or loss of reinforcement section. This allows for a change in the corrosion rate following initial cracking due to increased availability of oxygen at the cathode. All such models, however, rely on assumptions regarding the propagation rate of corrosion, which requires a supply of oxygen and water. The important point mentioned in paragraph 48 of the paper is that the supply of oxygen can be controlled by the moisture state and corrosion stifled under saturated conditions at the depth of the reinforcement. The controlling factors for the length of propagation period are cover depth, moisture content and temperature for a given concrete quality and environmental conditions. The importance of cover depth and its effect on the moisture content in the cover zone relates firstly to the initiation process (i.e. slow diffusion or rapid absorption of chloride ions) followed by the control of oxygen flux in the propagation phase. Understanding the link between these factors is vital if models derived from estimation of the residual life of existing structures are to be extrapolated to the design of new structures. It would therefore be useful if the authors could comment on whether they found any correlation between corrosion and moisture state for the Midlands Links structures that could be distinguished from the influence of depth of cover.

Figure 7 in the paper shows that for this concrete, minimum cover depths of at least $80-100 \mathrm{~mm}$ would be required to maintain adequately low chloride levels at the reinforcement, but nevertheless this is ignoring the point that the moisture content at this depth may be adequate to limit corrosion. We believe that as most observations (by ourselves and others in various publications) have been made on $100 \%$ ordinary Portland cement concrete which had somewhat too high a water/cement ratio with too low a cover for chloride conditions, extrapolation of these observations to better quality concrete with greater depths of cover may underestimate the benefits gained from the higher internal moisture content stifling the oxygen flux and lead to requirements for unnecessarily large depths of cover. Have the authors any comment?

The microclimatic conditions and critical moisture conditions are, perhaps, more definable in maritime conditions due to the known pattern of the fluctuating sea water level, provided that the effects of the external conditions are properly related to the moisture conditions within the concrete down to the reinforcement. In the past, wetting and drying conditions were often misinterpreted, with cyclical wetting and drying being considered to be the worst case. The damage is actually done by prolonged periods of drying following irregular periods of inundation by chloride-bearing water. If the conditions remained wet, the severity would be less. From Table 5 it would appear that the exposure to chloride at a particular location is more significant in bridge structures than the period of drying. This may indicate that differences in moisture conditions are less marked in bridge structures than in maritime conditions.

For assessment of the serviceability of a structure following corrosion of the reinforcement, it is clearly of importance to accurately assess the type of corrosion that has/will occur, i.e. uniform corrosion or pitting corrosion, since localised loss of section can have a much bigger impact than the same corrosion spread evenly along a bar or across several bars. Have the authors any data on the extent of and loss of crosssection due to pitting corrosion on the Midlands Links structures?

The authors of this paper have tackled the complex process of reinforcement corrosion in the pragmatic way of traditional engineering in order to achieve a practical model for the corrosion of reinforced concrete at our present level of understanding. It is only by attempting such simplifications from the evidence obtained from actual structures and by presenting the work for comment by others in this field that the development of models can be progressed. The authors are to be congratulated on their efforts.

Authors' reply

The authors wish to thank Messrs Slater and Sharp for their 
detailed consideration of our paper and we welcome the opportunity to expand on a number of points raised by the contributors in the hope that these will provide further insight to the modelling of reinforcement corrosion in concrete contaminated with chlorides.

Before responding to the detailed points raised by the contributors, it is important that we restate the context of the deterioration modelling presented in our paper. The model was developed specifically for use on highway structures where the source of chloride is from de-icing salts. Furthermore, it is towards existing deteriorating structures that the whole-life assessments procedures refer. The objective of the deterioration modelling process is to estimate the section loss of steel reinforcement and subsequent delamination of the cover concrete at the time of assessment and into the future. An appropriate method of structural assessment is then required to determine the residual life of the structure, which is the subject of a related paper also presented in Structures and Buildings. ${ }^{30}$ Theoretical corrosion models aimed at predicting corrosion losses in reinforced concrete structures had been developed by a number of researchers prior to our work, and these are referenced in the paper. However, we found these models required data that were not readily available and therefore not practical for general application. The model proposed by the authors presents an engineering empirical approach which makes use of extensive data collected during the repair of chloride-contaminated structures and utilises non-destructive test methods, readily available to the engineer, to apply the model to similar structures.

The contributors present a number of standards and guidance notes currently in draft which address the problem of durability in design. Although we agree that our paper provides a basis for the development of a much needed consensus on general corrosion model principles, it is important to clearly differentiate the objectives of deterioration modelling for the design of new structures compared to existing structures. The aim of deterioration modelling for existing structures has already been discussed above. For the design of new structures of traditional steel reinforced concrete there is a need to develop a rational methodology for predicting the longevity of a structure, where the principal variables are the concrete mix design and depth of cover. For the durability design of conventional reinforced concrete, the engineer needs to understand the effects the various concrete mix constituents have on the short- and long-term properties of the concrete. The deterioration models typically aim to predict parameters such as the diffusion characteristic of the concrete, which is then used in a Fickean diffusion model to determine the correct cover, given the particular environment and required service life. Cement replacements and the use of concrete admixtures present the designer with an almost limitless range of concrete mix designs, which is why prescriptive methods often fail to produce the desired durability. Through durability modelling, engineers are at least trying to understand the deterioration process in a rational way and the contributors' efforts to this end are to be commended. Of course there are many other possibilities for durable construction in extreme environments, such as the use of non-ferrous reinforcement, protective coatings and active techniques such as new-build cathodic protection; these two require modelling if we are to complete the picture.

In response to the contributors' detailed comments, the authors confirm that the data reviewed in the literature were from a wider range of concretes than would be expected to be found on the Midlands Links. We felt it important that the data collected for the model were placed into context with other data available in the public domain.

The 'effective' parameter values given in Table 1 are best-fit values for equation (3), just as the $220 \mathrm{~mm}^{2}$ /year is the best-fit (apparent) diffusion coefficient for the Midlands Links corrosion model. As such, there is no formal link between the theoretical and Midlands Links parameter values. No cement type is associated with the values given in Table 1 as they are derived from a best-fit analysis of data from numerous sources.

We felt that the steady-state increase in surface concentration was a realistic interpretation of events that occurred on the Midlands Links-that is, each year, more de-icing salt was added during the winter period. In a maritime environment, if a Fickean model were to be employed, it would be more justifiable to use a single value of surface concentration since the sea has a reasonably constant level of chloride. The chloride build-up was curtailed by the inclusion of guttering under the joints and the general replacement of de-icing salts with urea on the Midlands Links and so a detailed investigation of the stabilised surface value was deemed unnecessary. In addition, a sensitivity analysis demonstrated that, in the overall corrosion modelling of the Midlands Links, the effect of these parameters was negligible.

It is sensible to suggest that the build-up of surface concentration with time would be a significant difference between bridge and maritime structures, although the distinction may be better described by the source of chlorides. Immersed or partially immersed structures would have a constant source of chlorides and therefore it could be argued that they have a constant surface concentration for the purposes of a Fickean model. Windblown spray from a marine environment would build up to a threshold over a relatively short period of time before reaching an equilibrium with the environment. Bridges or other similar structures that have salt applied annually would be expected to build up over a longer period of time and may reach a higher equilibrium value. Specific data on rates of increase of surface concentration with time were not available from the Midlands Links since this would require monitoring the time at which deck joints failed, with profiles being collected annually. The data that were available were first collected in 1985 and were supplemented with a number of profiles taken after this date. The parameters developed for the model were those that gave a best fit to this data.

All chloride values in Table 1 are given with respect to the cement. The cement content on the Midlands Links was 18\%. The initial chloride content of the concrete samples being $0 \%$ was supported by the data, so no admixed chlorides were included in the modelling process. In the theoretical corrosion model, $0 \%$ initial chloride content is assumed to be indicative of negligible built-in chlorides. It is noted, however, that the 
values within both the theoretical and empirical corrosion models are complementary and so changes in this value (to reflect background levels of chlorides) would simply result in changes in the other parameter values. Final predicted corrosion levels would remain the same.

The contributors request that we comment on whether any correlation was found between corrosion and the moisture state of the Midlands Links structures that could be distinguished from cover depth. Aside from the local variations due to defective joints, all the beams are in a similar environment and so there is limited difference in exposure that would enable the effects of the moisture in the cover concrete to be assessed. The majority of the corroding crossbeams in the Midlands Links are suffering from chloride-induced corrosion. The chlorides ran off the deck through leaking joints and so there is an obvious correlation between the presence of runoff and the presence of chlorides that is not influenced by cover. In 1985 guttering was installed to control the runoff. This resulted in any beams not chloride-contaminated being effectively prevented from further contamination and so corrosion does not initiate, provided the cover is adequate to prevent corrosion as a result of carbonation.

The three-stage approach was considered when looking at the empirical corrosion model. However, we decided that it would be difficult to take the model beyond initiation of corrosion as any limit state of cracking or spalling would involve modelling of both the expansive properties of the corrosion and the tensile properties of concrete and this was not thought to be practical at the time.

Using Fig. 7 to suggest that cover of $80-100 \mathrm{~mm}$ would prevent corrosion is not correct. The model was not developed to be reverse applied to produce durable concrete: it was developed to estimate the time taken for corrosion to initiate in a structure where the majority of the cover was significantly lower than this value. In addition to the availability of oxygen and moisture at this depth, the contributors of the discussion may want to consider the cracking that would take place in the cover at these values.

Table 5 was derived solely on the basis of exposure to chlorides and did not take account of the sorptivity of the concrete that produces the accelerated chloride penetration found after long periods of drying. In the UK, chlorides are typically applied during the winter months, and the concrete has typically been exposed to a damp autumn prior to this. It was felt that the prolonged periods of drying followed by soaking with salt-laden water rarely occurs.

With regard to pitting and general corrosion, chloride-induced depassivation of steel reinforcement in concrete is a classical example of pitting corrosion. The vast majority of the 10000 corrosion sites used in the production of the model were predominantly caused by pitting, although some may have been subject to more general atmospheric corrosion once extensive delamination had occurred. If the contributors are distinguishing between expansive (red rust) and non-expansive (black rust) corrosion products, in using the terms 'general corrosion' and 'pitting', as is often the case in civil engineering, then it was not possible to distinguish between the two types during the data analysis.

\section{REFERENCES}

16. Building RESEARch Establishment Ltd (BRE)/DEPARTMENT OF THE ENVIRONMENT, TRANSPORT AND THE REGIONS (DETR). Report of Seventh DETR Programme for Durability of Concrete Construction. BRE, Watford, 16 February 2000.

17. EUROPEAN COMmitTeE FOR STANDARdisAtion. Concrete. EN 206-1, 2000.

18. BRITISH STANDARDS InSTITUTION. Concrete. BS 8500: Parts $1-4$. 4th draft, Complementary British Standard to EN 206-1. BSI, June 2000.

19. Concrete Society. Discussion document: Developments in Durability Design and Performance-based Specification of Concrete. The Concrete Society, 1996.

20. MARSH B. An introduction to UK durability provisions for use with European Standard EN206. Concrete, 2000, 34, No. 6, June, 36-37.

21. MARSH B. The European classification of exposure environment for concrete. Concrete, 2000, 34, No. 6, June, $38-39$.

22. Higgins D. Carbonation induced corrosion. Concrete, 2000, 34, No. 6, June, 40-41.

23. CATHER R. Concrete in chloride environments. Concrete, 2000, 34, No. 6, June, 42-43.

24. MURE N. Concrete in aggressive chemical environments. Concrete, 2000, 34, No. 6, June, 44-45.

25. HARRISON T. Resisting freeze/thaw attack. Concrete, 2000, 34, No. 6, June, 46-47.

26. SHARP B. N. Durability of maritime concrete in BS 6349. Part 1: 2000. Concrete, 2000, 34, No. 6, June, 48-50.

27. BRITISH STANDARDS InSTITUTION. Maritime Structures, Code of Practice for General Criteria. BSI, July 2000, BS 6349: Part 1.

28. Bamforth P. A., Price W. F. and Emerson M. $A n$ International Review of Chloride Ingress into Structural Concrete. Report TRL 359, Thomas Telford, 1997.

29. HartT W. H., LeE S. K. and Costa J. E. Condition assessment and deterioration projection for chloride contaminated reinforced concrete structures. Repair and Rehabilitation of Reinforced Concrete Structures: The State of the Art, Proceedings of an International Seminar, Workshop and Exhibition, Moracaibo, April/May 1997.

30. Sarveswaran V., Roberts M. B. and WARD J. A. Reliability assessment of deteriorating reinforced concrete beams. Proceedings of the Institution of Civil Engineers Structures and Buildings, 2000, 140, Aug., 239-247, paper 11966. 